\title{
Detection of Pneumocystis carinii among children with chronic respiratory disorders in the absence of HIV infection and immunodeficiency
}

\author{
C. CONTINI, MARIA PIA VILLA*, R. ROMANI†, R. MEROLLA*, S. DELIA† and R. RONCHETTI* \\ Institute of Infectious and Respiratory Diseases, University of Ferrara, *Fourth Pediatric Clinic and \\ †Department of Infectious and Tropical Diseases, La Sapienza University, Rome, Italy
}

\begin{abstract}
A nested polymerase chain reaction (PCR) assay was investigated for detection of Pneumocystis carinii in 96 respiratory tract specimens from 82 children, of whom 28 were immunocompetent but with chronic lung disorders (CLD), eight had AIDS and $P$. carinii pneumonia (PCP), 16 had AIDS but no respiratory symptoms, and 30 were healthy immunocompetent children. Gomori methenamine silver stain (GMS) and indirect immunofluorescence assay (IFA) were performed in parallel. Of 36 specimens from children with CLD, 12 were $P$. carinii PCR-positive compared to 10 positive by GMS-IFA. Of eight specimens from children with AIDS and PCP, seven were $P$. cariniipositive by PCR and six by GMS-IFA, and of 22 specimens from HIV-positive children without respiratory symptoms, two were positive by PCR and none by GMS-IFA. $P$. carinii DNA was also detected by PCR in blood samples from four children with $P$. carinii-positive nasopharyngeal aspirates. Specimens from healthy children were negative for $P$. carinii by both PCR and GMS-IFA. Of the seven children with CLD, who were $P$. carinii-positive, two had clinical and microbiological improvement with co-trimoxazole treatment, two improved initially but relapsed, and one had $P$. carinii cysts persistently in follow-up specimens despite co-trimoxazole treatment. These results suggest an association between $P$. carinii and exacerbations of CLD in childhood, in the absence of HIV infection or other immunodeficiency syndromes.
\end{abstract}

\section{Introduction}

In immunocompromised patients, and particularly in those with AIDS, Pneumocystis carinii pneumonia (PCP) is one of the most frequent opportunist infections. It may result from a pneumocystis infection de novo or from reactivation of latent childhood infection.

Reports of PCP in non-immunocompromised patients are rare and appeared before testing for HIV and the detailed assessment of immune function were available [1]. DNA amplification studies have failed to detect $P$. carinii in sputum or autopsy lung tissue from immunocompetent patients $[2,3]$, or from bronchoalveolar lavage fluid except for patients with small cell lung cancer [4]. However, others have reported the detection of $P$. carinii in specimens from healthy adults without immunological impairment or evidence of neoplasms or HIV infection [5-7]. P. carinii has also been detected

Received 14 June 1996; revised version received 27 June 1997; accepted 8 Aug. 1997.

Corresponding author: Professor C. Contini. by conventional stains in non-immunosuppressed patients with chronic obstructive lung disease [8].

This study evaluated the presence of $P$. carinii in respiratory specimens from immunocompetent children with chronic lung diseases (CLD). P. carinii detection was investigated by conventional stains and by a nested polymerase chain reaction (PCR) assay with rat-derived $P$. carinii oligonucleotides known to show significant homology with $P$. carinii found in man. In a previous study, these oligonucleotides proved to be efficient primers for amplification of $P$. carinii DNA from both rats and human patients with PCP and did not amplify DNA from a range of other pathogens including fungi [9].

\section{Materials and methods}

\section{Clinical specimens and patients}

A total of 96 respiratory specimens including nasopharyngeal aspirates (NPA) and induced sputum samples was assayed for $P$. carinii. Clinical specimens 
and the study population consisted of: group 1,36 specimens from 28 HIV-seronegative children (1-14 years) according to the CDC criteria, with normal Band T-lymphocyte counts, T-cell subsets and total immunoglobulins, who presented with various respiratory disorders; group 2, eight specimens from eight HIV-positive children with PCP diagnosed on clinical and radiological findings of whom six were $P$. cariniipositive by staining (one patient had earlier Toxoplasma gondii encephalitis and was receiving anti- $P$. carini specific treatment at the time of sampling); group 3, 22 specimens from 16 HIV-positive patients without respiratory symptoms or chest X-ray abnormalities, of whom 10 presented with a high degree of immunosuppression (CD4+ lymphocyte counts $<200 / \mathrm{mm}^{3}$ ) and were receiving specific prophylaxis against $P$. carinii at the time of specimen collection; group 4, 30 specimens from 30 healthy, afebrile infants without active pulmonary infection who were not receiving immunosuppressive drugs and were age-matched and sex-matched for group 1.

Patients with CLD (group 1) were recruited between Nov. 1992 and Jan. 1995 from the Paediatric Institution of Rome after approval of the local Ethics Committee. An NPA was collected at admission for all patients. Some patients were evaluated prospectively to establish clinical or microbiological response, or both, to treatment and required further specimens $(\mathrm{n}=$ 1-6). Induced sputum samples were also assayed from five patients. Informed consent to perform anti-HIV testing was obtained. Nine HIV-infected children (group 3) had further single specimens which were investigated retrospectively for $P$. carinii after discharge from hospital, usually coincident with disappearance of clinical symptoms.

Respiratory specimens were assayed for $P$. carinii by PCR, indirect immunofluorescence assay (IFA) and tinctorial Gomori methenamine staining (GMS). Samples were also screened for bacteria, fungi, mycoplasmas, Mycobacterium tuberculosis and respiratory syncitial virus. The presence of other viruses, such as cytomegalovirus, coronaviruses and rhinoviruses, was not investigated. Single or muliple blood samples were also obtained from each patient and the controls and these were tested by PCR.

\section{Specimen processing}

NPA specimens were collected on admission as described previously [10]. NPA and induced sputa were liquefied with sputolysin (6.5 mM dithiothreitol; Unipath, Basingstoke) and then vortex mixed with glass beads for $3 \mathrm{~min}$. An equal volume of phosphate-buffered saline (PBS, $\mathrm{pH}$ 7.2) was added and samples were centrifuged at 3000 $\mathrm{rpm}$ for $15 \mathrm{~min}$. A portion of the pellet was resuspended in $1 \mathrm{ml}$ of PBS and stored until required for PCR assay. A further portion was either smeared on IFA slides or stained by a rapid GMS [11].

\section{Immunofluorescence antibody test (IFA)}

Specimens were fixed in cold acetone for $10 \mathrm{~min}$ and then treated with trypsin $(2.5 \mathrm{~g} / \mathrm{L})$ to remove proteins covering antigenic sites of the pathogen. Anti-P. carinii monoclonal antibodies (MAbs) (Monofluo kit Pneumocystis, Diagnostic Pasteur, Marnes La Coquette, France) prepared against human $P$. carinii cysts and specific for cyst-wall antigen were employed [12]. An IFA specimen was considered positive if two or three good cysts were seen in at least three high power fields. Both the IFA and GMS preparations were examined blindly by different people.

\section{Polymerase chain reaction procedure (PCR)}

Approximately $1 \mathrm{ml}$ of sample was centrifuged at $15000 \mathrm{rpm}$ for $3 \mathrm{~min}$; pellets were resuspended in $400 \mu \mathrm{l}$ of proteinase $\mathrm{K}$ buffer containing $500 \mu \mathrm{g}$ of proteinase $\mathrm{K}$ (Boehringer Mannheim Biochemicals). After overnight incubation at $37^{\circ} \mathrm{C}$, DNA was extracted by phenol-chloroform-isoamyl alchohol followed by ethanol precipitation. Two primer sets based on the chromosomal rRNA sequence of rat-derived $P$. carinii were used in a nested PCR as described previously [9]. The amplification mix contained $10 \mathrm{mM}$ Tris- $\mathrm{HCl}(\mathrm{pH}$ 8.3 , supplemented with $50 \mathrm{mM} \mathrm{KCl}$ ), $200 \mathrm{mM}$ of each deoxynucleotide triphosphate, $0.25 \mathrm{mM}$ of each primer, AmpliTaq DNA Polymerase $25 \mathrm{U} / \mathrm{ml}$, and $2.5 \mathrm{mM}$ $\mathrm{MgCl}_{2}$ in a final reaction volume of $50 \mu \mathrm{l}$ (all reagents from Perkin-Elmer, Norwalk, USA). Samples were subjected to initial amplification with external primers (35 cycles of $1 \mathrm{~min}, 94^{\circ} \mathrm{C} ; 1 \mathrm{~min}, 50^{\circ} \mathrm{C} ; 2 \mathrm{~min}, 72^{\circ} \mathrm{C}$ ) followed by re-amplification with inner primers $(25$ cycles). The DNA products of $378 \mathrm{bp}$ for the external primers and $312 \mathrm{bp}$ for the inner primers were detected by gel electrophoresis and staining with ethidium bromide. The PCR product (10- $\mu 1$ samples) was further analysed by Southern hybridisation with a radiolabelled oligonucleotide probe. Samples were declared positive if a band of appropriate size was detected by autoradiography.

For blood PCR, peripheral blood mononuclear cells (PBMCs) were isolated by density gradient centrifugation (Lymphoprep, Nycomed) within $2 \mathrm{~h}$ of collection. DNA was extracted by the method of Kawasaki [13]. PBMCs were incubated overnight with proteinase $K$ and DNA was extracted as above.

Precautions appropriate for the prevention of crosscontamination of PCR assays were strictly observed [14]. Each stage was performed in separate rooms, pipettes and bottles were regularly autoclaved and gloves were changed frequently.

Controls. For each assay, positive and negative controls were included. Purified $P$. carinii cysts extracted from infected human lung tissue (autopsy material) and BAL specimens from AIDS patients with documented PCP were used as positive controls. Lung tissue homo- 
genates prepared from uninfected human lung with no detectable $P$. carinii or other respiratory pathogens, and BAL specimens from immunocompetent patients, negative for $P$. carinii or fungi at time time of their collection, served as negative controls. The PCR method was also tested with a number of other organisms (Toxoplasma gondii, Cryptococcus neoformans, Candida albicans, C. tropicalis, Aspergillus fumigatus) to assess specificity. A buffer negative control was also included to test for cross-contamination.

\section{Results}

Clinical and laboratory data are summarised in Tables 1 and 2.

Group 1. Among the 28 immunocompetent children with CLD, asthma $(n=4)$ and chronic bronchitis (8) were the most frequent diagnoses. Other underlying conditions included immotile cilia syndrome (1) and middle lobe syndrome (2), atopy and respiratory allergy with recurrent episodes of bronchopneumonia (2) and bronchiolitis with otitis media (2). Principal symptoms leading to admission were productive cough for at least 3 months of a year according to published
CLD definition [15] with fever of $\leqslant 7$ days. In one patient, the duration of fever had lasted several weeks and had not responded to antibiotic treatment. Chest radiological findings included bilateral infiltrates in three patients, emphysema in five, diffuse interstitial infiltrate in one and bronchovascular markings in five. In patients for whom arterial blood gas values were determined, values were normal.

Of 36 NPA samples from these patients, 12 (33\%) were positive for $P$. carinii by PCR (seven patients), compared to $10(27.7 \%)$ positive by GMS and IFA (six patients). All positive PCR specimens produced a strong band of amplified DNA easily identified after ethidium bromide staining. All GMS and IFA positive specimens were positive by both staining techniques. Induced sputum specimens were available from five patients with $P$. carinii-positive NPA; these were all positive by both PCR and GMS/IFA. The characteristics, treatment and outcome of the seven CLD patients positive for $P$. carinii are shown in Table 2 . Other potential respiratory pathogens were isolated from four of these patients, including Staphylococcus aureus, Streptococcus pneumoniae, Pseudomonos spp. and Moraxella catarrhalis. Five children were treated with co-trimoxazole; two improved, two improved initially but then relapsed, and one had persistent $P$.

Table 1. Results of $P$. carinii investigation on respiratory specimens from different patient groups

\begin{tabular}{lccc}
\hline & & Number of samples positive for $P$ carinii by \\
Patient group & Number of NPA samples & PCR & GMS-IFA \\
\hline Group 1 $(\mathrm{n}=28)^{*}$ & 36 & $12(7)^{*}$ & $10(6)$ \\
Group 2 $(\mathrm{n}=8)$ & 8 & $7(7)$ & $6(6)$ \\
Group 3 $(\mathrm{n}=16)$ & 22 & $2(1)$ & 0 \\
Group $4(\mathrm{n}=30)$ & 30 & 0 & 0 \\
\hline
\end{tabular}

NPA, nasopharyngal aspirate; GMS-IFA, gomori methenamine stain - indirect immunofluorescence assay.

* ( ) number of patients.

Table 2. Clinical and microbiological findings among children positive for $P$. carinii with chronic respiratory diseases

\begin{tabular}{|c|c|c|c|c|c|c|c|}
\hline \multirow[b]{3}{*}{ Case no. } & \multirow[b]{3}{*}{ Underlying disease } & \multicolumn{3}{|c|}{ P. carinii detected by } & \multirow{3}{*}{$\begin{array}{l}\text { Other } \\
\text { pathogens } \\
\text { isolated }\end{array}$} & \multirow{3}{*}{$\begin{array}{l}\text { Antimicrobial } \\
\text { therapy }\end{array}$} & \multirow[b]{3}{*}{ Outcome } \\
\hline & & \multicolumn{2}{|c|}{ NPA } & \multirow{2}{*}{$\begin{array}{l}\text { PBMC } \\
\text { PCR }\end{array}$} & & & \\
\hline & & GMS-IFA & PCR & & & & \\
\hline 1 & Middle lobe syndrome & Yes & Yes & Yes & None & TMP-SMX & $\begin{array}{l}\text { Microbiological } \\
\text { improvement }\end{array}$ \\
\hline 2 & Middle lobe syndrome & Yes & Yes & No & $\begin{array}{l}S . \text { aureus, Str. } \\
\text { pneumoniae, } M . \\
\text { catarrhalis }\end{array}$ & TMP-SMX & $\begin{array}{l}\text { Improvement, } \\
\text { then relapse }\end{array}$ \\
\hline 3 & Middle lobe syndrome & Yes & Yes & No & $\begin{array}{l}\text { Str. pneumoniae, } M \text {. } \\
\text { catarrhalis }\end{array}$ & TMP-SMX & $\begin{array}{l}\text { Improvement, } \\
\text { then relapse }\end{array}$ \\
\hline 4 & $\begin{array}{l}\text { Chronic bronchitis; post-measles } \\
\text { pneumonia }\end{array}$ & No & Yes & No & $\begin{array}{l}\text { Pseudomonas spp. } \\
\text { Str. pneumoniae }\end{array}$ & Other & $\begin{array}{l}\text { Improvement, } \\
\text { then relapse }\end{array}$ \\
\hline 5 & Chronic bronchitis & Yes & Yes & No & $\mathrm{ND}$ & TMP-SMX & $\begin{array}{l}\text { Clinical and } \\
\text { microbiological } \\
\text { improvement }\end{array}$ \\
\hline 6 & Chronic bronchitis & Yes & Yes & No & ND & Other & $\begin{array}{l}\text { Improvement, } \\
\text { then relapse }\end{array}$ \\
\hline 7 & FUO; chronic bronchitis & Yes & Yes & No & S. aureus & TMP-SMX & $\begin{array}{l}\text { Persistence of } P \text {. } \\
\text { carinii cysts }\end{array}$ \\
\hline
\end{tabular}

NPA, nasopharyngeal aspirate; GMS, gomori methenamine stain; IFA, indirect immunofluorescent assay; FUO, fever of unknown origin; other, antimicrobial therapy without known efficacy against $P$. carinii, ND, not determined; PBMC, peripherial blood monocytes; TMP-SMX, cotrimoxazole. 
carinii cysts in follow-up specimens. Two children were treated with other antibiotics with no activity against $P$. carinii, both improved initially but relapsed.

Group 2. Of the eight HIV-positive patients with probable PCP, two presented with productive or dry cough without dyspnoea, four had fever and dyspnoea, and two had dyspnoea only. Radiological signs varied from perihilar markings to bilateral interstitial shadowing. Five patients were hypoxaemic. In six patients, PCP had been confirmed previously by GMS. Of the eight specimens collected from these patients, seven $(87.5 \%)$ were PCR-positive, including the six known GMS-positive specimens which were also confirmed as positive by IFA. The single PCR-positive, GMS-IFAnegative specimen was from the child receiving antiPCP proplyaxis.

Group 3. The other 16 HIV- infected children had advanced AIDS but no pulmonary symptoms. In this group $P$. carinii DNA was also detected in two $(9 \%)$ specimens obtained from one patient.

Group 4. All 30 control children were negative for $P$. carinii by PCR, GMS and IFA.

P. carinii DNA was detected in four blood specimens: one from a CLD case with NPA samples positive for $P$. carinii by both microscopy and PCR (case 1, Table 2), two from HIV-infected patients with documented PCP and with NPA positive by both staining and PCR, and one from an HIV-infected patient with no respiratory symptoms but with an NPA positive by PCR only.

\section{Discussion}

In HIV-positive children and adults, PCP is the most common AIDS-defining diagnosis, occurring in 30 $50 \%$ of all cases. In children, PCP has also been described in patients with predisposing conditions such as neoplasms, organ transplants, hypogammaglobulinaemia and immunosuppressive therapy [16]. Subclinical $P$. carinii infection has been recognised at autopsy in healthy immunocompetent children [17]. Furthermore, specific antibodies have been shown to develop by the age of 4 years, indicating ubiquitous early exposure to the organism, $[18,19]$.

The present study investigated the role of $P$. carinii in immunocompetent children with CLD. $P$. carinii was detected by PCR in 12 of 36 NPA specimens from children admitted with exacerbations of CLD; 10 of these were confirmed by IFA and GMS. In contrast, $P$. carinii was not detected in NPA samples from 30 healthy children. However, the role of $P$. carinii in the respiratory disease of children with CLD was unclear. Cross-contamination between cases was unlikely, as bronchoscopes or other special equipment were not required to obtain NPA specimens. Several authors have suggested that $P$. carinii may be a transmissible pathogen in both animals and man $[20,21]$. However, none of the children positive for PCP was known to have been exposed to patients with PCP. The isolation of co-pathogens in these patients is not surprising. Culture results of NPAs and other respiratory samples are often difficult to interpret because of the carriage of potential respiratory pathgens in the upper airways. Furthermore, clinical and radiological features were non-specific in many study patients some of whom were already receiving antimicrobial therapy, further complicating the clinical and microbiological picture. Although the role of $P$. carinii in exacerbations of CLD needs further clarification, the inflammatory reaction and bronchial obstruction seen in CLD might permit proliferation of $P$. carinii in the lung.

Two CLD children with $P$. carinii improved with cotrimoxazole therapy, suggesting that $P$. carinii may have been responsible for the worsening of their pulmonary disease. Four patients improved on cotrimoxazole but then relapsed clinically and one was found to have $P$. carinii cysts in follow-up specimens. These failures may have been related to relapse or re-infection. Recurrent episodes of PCP are thought to be caused by re-infection rather than by reactivation $[22,23]$.

Overall, PCR detected five more positive samples than GMS and IFA. This may be related to the ability of PCR to detect DNA from both trophozoite and cyst forms; IFA and GMS are specific for cysts only, and may be negative in specimens with a low cyst load. Cross-contamination with $P$. carinii DNA from positive samples was unlikely as negative controls were included in all PCR runs.

Sputum is difficult to collect from infants and young children and NPAs are often relied upon. Our detection of $P$. carinii by both PCR and GMS-IFA in NPA samples confirms the data from other groups showing that NPA is a useful analytical sample for the diagnosis of PCP among HIV-infected and leukaemic infants $[24,25]$.

Among the eight HIV-positive children with established PCP, one had a negative PCR result. The failure of PCR to amplify DNA in this specimen was probably due to long-term anti-PCP treatment, but loss of DNA during storage or routine manipulation could not be ruled out.

One of the PCR-postive GMS-IFA-negative specimen was from an HIV-positive child, who had taken prophylaxis for PCP; this patient had received both co-trimoxazole and aerosolised pentamidine. PCP prophylaxis may contribute to under-detection of $P$. carinii by conventional staining methods by reducing the number of organisms present in the respiratory 
tract [26]. In this situation PCR positivity may represent subclinical colonisation with $P$. carinii. PCR examination of serial specimens over time may offer prognostic information about the development of symptomatic PCP as well as the efficacy of current treatment regimens.

The lack of false positive PCR results among healthy children suggests that the specificity of the PCR assay for $P$. carinii was high.

Four children (1, CLD; 3, AIDS) with positive NPAs for $P$. carinii also had detectable $P$. carinii-specific amplification products in PBMCs, confirming previous data from rats and human patients with PCP [11, 21, $27,28]$. Recently, $P$. carinii sequences were detected by PCR in serum from patients with PCP [29]. The practical value of $P$. carinii $\mathrm{PCR}$ assays of whole blood, serum or PBMCs as a diagnostic tool for PCP remains to be determined.

Further work is required to determine whether longterm carriage of $P$. carinii alone or with accompanying co-pathogens contributes to exacerbations of CLD and whether appropriate prophylactic or therapeutic regimens should be considered in these patients.

This work was supported by the Italian Ministry of University and Scientific Research (grant No. 2.196.507, 40\% and grant no. $95 / 60 / 06 / 026,60 \%$ ) and Fondazione Carife, Italy.

\section{References}

1. Sanders-Laufer D, DeBruin W, Edelson PJ. Pneumocystis carinii infections in HIV-infected children. Pediatr Clin North Am 1991; 38: 69-88

2. Leigh TR, Wakefield AE, Peters SE et al. Detection of subclinical Pneumocystis carinii infection with the polymerase chain reaction in asymptomatic renal and heart-lung transplant recipients receiving no prophylaxis against Pneumocystis carinii. Thorax 1991; 46: 743.

3. Peters SE, Wakefield AE, Sinclair K, Millard PR, Hopkin JM. A search for Pneumocystis carinii in post-mortem lungs by DNA amplification. J Pathol 1992; 166: 195-198.

4. Matusiewicz SP, Fergusson RJ, Greening AP, Crompton GK, Burns SM. Pneumocystis carinii in bronchoalveolar lavage fluid and bronchial washings. BMJ 1994; 308: 1206-1207.

5. Contini C, Romani R, Vullo V, Delia S, Sorice F. Does laboratory recovery of Pneumocystis carinii always mean clinically significant disease? AIDS 1992; 6: 1558-1559.

6. Stiller RA, Paradis IL, Dauber JH. Subclinical pneumonitis due to Pneumocystis carinii in a young adult with elevated antibody titers to Epstein-Barr virus. J Infect Dis 1992; 166: 926-930.

7. Palange P, Serra P, Di Sabato F, Contini C, Giacovazzo M Pneumocystis carinii pneumonia in a patient with chronic obstructive pulmonary disease but no evident immunoincompetence. Clin Infect Dis 1994; 19: 543-44.

8. Calderón EJ, Regordán C, Medrano FJ, Ollero M, Varela JM. Pneumocystis carinii infection in patients with chronic bronchial diseaes. Lancet 1996; 347: 977.

9. Lipschick GY, Gill VJ, Lundgren JD et al. Improved diagnosis of Pneumocystis carinii infection by polymerase chain reaction on induced sputum and blood. Lancet 1992; 340: 203-206.

10. Heiskanen-Kosma T, Korppi M, Kleemola M, Heinonen K RNA hybridization for Mycoplasma pneumoniae: a new tool for following the epidemiological situation. Acta Paediatr 1992; 81: 705-706.

11. Musto L, Flanigan M, Elbadawi A. Ten-minute silver stain for Pneumocystis carinii and fungi in tissue sections. Arch Pathol Lab Med 1982; 106: 292-294.

12. Beauvais B, Sarfati C, Gerber F, Lariviere M, Hirsch A. Etude comparative de deux techniques de coloration classiques et d'un test d'iimmunofluorescence indirect apliqués à la recherche de Pneumocystis carinii dans le liquide de lavage broncho-alvéolaire et l'expetroration induite des sujets HIV+ [Comparative study of two classical techniques of coloration and an indirect immunofluorescent assay applied to research on Pneumocystis carinii in the bronchoalveolar lavage fluid and induced symptom in HIV+VE patients.] Ann Biol Clin 1989; 47: $635-639$

13. Kawasaki ES. Sample preparation from blood, cells, and other fluids. In: Innis (ed) PCR protocols: a guide to methods and applications. San Diego, Academic Press. 1990: 146-152.

14. Kwok S, Higuchi R. Avoiding false positives with PCR. Nature 1989; 339: 237-238

15. Vermeire P. Definition of COPD. In: Herwaarden CLA, Repine JE, Vermeire $P$, van Weel C (eds) COPD: diagnosis and treatment. Amsterdam, Excerpta Medica. 1996: 1-11.

16. Stagno S, Pifer LL, Hughes WT, Brasfield DM, Tiller RE. Pneumocystis carinii pneumonitis in young immunocompetent infants. Pediatrics 1980; 66: 56-62.

17. Sheldon WH. Subclinical pneumocystis pneumonitis. Am J Dis Child 1959; 97: 287-297.

18. Pifer LL, Hughes WT, Stagno S, Woods D. Pneumocystis carinii infection: evidence for high prevalence in normal and immunosuppressed children. Pediatrics 1978; 61: 35-41.

19. Peglow SL, Smulian AG, Linke MJ et al. Serologic responses to Pneumocystis carinii antigens in health and disease. $J$ Infect Dis 1990; 161: 296-306.

20. Walzer PD. Pneumocystis carinii - new clinical spectrum? $N$ Engl J Med 1991; 324: 263-265.

21. Sepkowitz K, Schuluger N, Godwin T, Armstrong D, Cerami A, Bucala R. DNA amplification in experimental pneumocystosis: characterization of serum Pneumocystis carinii DNA and potential $P$. carinii carrier states. J Infect Dis 1993; 168: $421-426$.

22. Lee C-H, Lu J-J, Bartlett MS et al. Nucleotide sequence variation in Pneumocystis carinii strains that infect humans. $J$ Clin Microbiol 1993; 31: 754-757.

23. Keely SP, Stringer JR, Baugham RP, Linke MJ, Walzer PD, Smulian AG. Genetic variation among Pneumocystis carinii hominis isolates in recurrent pneumocystosis. $J$ Infect Dis 1995; 172: 595-598.

24. Hague RA, Burns SE, Mok JYQ, Yap PL. Diagnosis of Pneumocystis carinii pneumonia from non-invasive sampling of respiratory secretions. Arch Dis Child 1990; 65: 1364-1365.

25. Richards CG, Wakefield AE, Mitchell CD. Detection of Pneumocystis DNA in nasopharyingeal aspirates of leukaemic infants with pneumonia. Arch Dis Child 1994; 71: 254-255.

26. Levine SJ, Masur H, Gill VJ et al. Effect of aerosolized pentamidine prophylaxis on the diagnosis of Pneumocystis carinii pneumonia by induced sputum examination in patients infected with the human immunodeficiency virus. Am Rev Respir Dis 1991; 144: 760-764.

27. Contini C, Cultrera R, Merolla R. PCR for detection of Pneumocystis carinii in blood cells. J Clin Microbiol 1995; 33: 1431-1432.

28. Contini C, Mastrantoni S, Romani R, Cultrera R, Delia S Evidence of Pneumocystis carinii in cell line cultures infected with peripheral blood mononuclear cells from AIDS patients with $P$. carinii pneumonia. J Med Microbiol 1995; 42 394-398.

29. Atzori C, Lu J-J, Jiang B et al. Diagnosis of Pneumocystis carinii pneumonia in AIDS patients by using polymerase chain reactions on serum specimens. $J$ Infect Dis 1995; 172 $1623-1626$. 